\title{
The Gilliam Autism Rating Scale (GARS - 2), a pilot study for the
} Greek autistic population

\author{
Dionysios Tafiadis*1, Glykeria Loli ${ }^{1}$, Eupraxia Tsanousa ${ }^{2}$ and Maria Tafiadi ${ }^{3}$
}

\author{
Address: ${ }^{1}$ Department of Speech Language Therapy, Technological Institute of Ioannina, Ioannina Greece, ${ }^{2}$ Department of primary education, \\ University of Ioannina, Ioannina, Greece and ${ }^{3}$ Department of Mathematics, University of Patras, Patras, Greece \\ * Corresponding author
}

\author{
from International Society on Brain and Behaviour: 3rd International Congress on Brain and Behaviour \\ Thessaloniki, Greece. 28 November - 2 December 2007 \\ Published: 17 April 2008 \\ Annals of General Psychiatry 2008, 7(Suppl I):SI9I doi:I0.II86/I744-859X-7-SI-SI9I
}

This abstract is available from: http://www.annals-general-psychiatry.com/content/7/SI/SI9 |

(C) 2008 Tafiadis et al.; licensee BioMed Central Ltd.

\section{Background}

The present research project (a pilot study) aims to examine and to validate the Gilliam autism rating scale to the Greek population, and what the standardization probabilities are.

\section{Materials and methods}

In this research took part 30 participants (15 non autistic and 15 autistic subjects), recruited from the Greek health settings, at city of Ioannina Greece. The sample was taken in random order. The questionnaire, which was administrated, was a rating scale that originally created by James Gilliam. GARS-2 is a revised version of the Gilliam Autism Rating Scale (GARS) for identifying and diagnosing autism in individuals ages 3 through 22 years. It contains new normative data. All 42 test items are based on the most current definitions of autism by the Diagnostic and Statistical Manual of Mental Disorders: Fourth EditionText Revision (DSM-IV TR) [1] and the Autism Society of America [2]. Test items are divided into three subscales: Stereotyped Behaviors, Communication, and Social Interaction.

\section{Results}

Statistical analysis of the data revealed that the Test items, which are divided into three subscales: Stereotyped Behaviours, Communication, and Social Interaction, did have affection on the autistic quotient for the autistic sample (using a linear model and regression). No affection on the autistic quotient was noticed for the non - autistic sample. Non-statistical significant differences were found in both autistic and non - autistic sample, between the autistic quotient and sex (autistic, $\mathrm{t}=0.24, \mathrm{df}=28, \mathrm{NS}$ ), and non - autistic sample $(\mathrm{t}=0.13, \mathrm{df}=28, \mathrm{NS})$, autistic quotient and age (autistic, $\mathrm{t}=-0.11, \mathrm{df}=28, \mathrm{NS}$ ) and non autistic sample $(\mathrm{t}=-0.31, \mathrm{df}=28, \mathrm{NS})$.

\section{Conclusions}

It seams positive that the GARS can go under standardization for the Greek autistic population. From the analysis of the data it is obvious and for both Greek autistic sample that every subscale does not interprets the autistic quotient by itself but the three of then in summary, as it is for the US population. Finally the advantages and the disadvantages of the scale were also discussed.

\section{References}

I. Diagnostical and Statistical manual of mental disorders. 4th Ed edition. Washington, DC; 1994.

2. Definition of Autism. In The Advocate: Newsletter of the Autism Society of America Silver Spring, MD; 1994. 